\title{
A Compact UWB Antenna with a Quarter-Wavelength Strip in a Rectangular Slot for 5.5 GHz Band Notch
}

\author{
Pichet Moeikham, Chatree Mahatthanajatuphat, and Prayoot Akkaraekthalin \\ Faculty of Engineering, King Mongkut's University of Technology North Bangkok, 1518 Pracharat 1 Road, Bangsue, \\ Bangkok 10800, Thailand \\ Correspondence should be addressed to Pichet Moeikham; moei76@hotmail.com
}

Received 9 September 2012; Revised 22 November 2012; Accepted 19 December 2012

Academic Editor: Renato Cicchetti

Copyright (C) 2013 Pichet Moeikham et al. This is an open access article distributed under the Creative Commons Attribution License, which permits unrestricted use, distribution, and reproduction in any medium, provided the original work is properly cited.

\begin{abstract}
The limitation of the electromagnetic interferences (EMIs) caused by UWB radiating sources into WLAN/WiMAX communication systems operating in the frequency band located around $5.5 \mathrm{GHz}$ requires the adoption of appropriate design features. To this purpose, a notch filter integrated into an UWB antenna, which is able to ensure a better electrical insulation between the two mentioned communication systems with respect to that already presented by the authors Moeikham et al. (2011), is proposed in this paper. The proposed filter, consisting in a rectangular slot including a quarter-wavelength strip integrated on the lower inner edge of the UWB radiating patch, is capable of reducing the energy emission in the frequency range between 5.1 and $5.75 \mathrm{GHz}$ resulting in lower EMIs with sensible electronic equipments working in this frequency band. The antenna structure has no need to be tuned after inserting the rectangle slot with a quarter-wavelength strip. The proposed antenna has potential to minimize the EMIs at a frequency range from 5.1 to $5.75 \mathrm{GHz}$. The radiation patterns are given nearly omnidirectional in $x y$ plane and likely bidirectional in $y z$ plane at all frequencies by the proposed antenna. Therefore, this antenna is suitable to apply for various UWB applications.
\end{abstract}

\section{Introduction}

The ultra-wideband (UWB) monopole antenna has attracted much attention to design on a printed planar structure due to the fact that it could be designed with various shapes. Many inherent advantages exhibit on printed planar structure such as low profile, low cost, compact size, and ease for manufacture. Therefore, the printed planar antennas are popular rapidly. The printed antenna is preferably utilized with microstrip line or coplanar waveguide $(\mathrm{CPW})$ as a feeding element. It is apparent in many pieces of literature that the compact UWB antennas based on the printed planar structure have been presented. For examples, the paper [1] presented development of a triangular CPW-fed printed antenna with specific ground plane shape. The antenna in [2] was designed by using a rectangular monopole M-shaped notch at the bottom patch with taper and T-shaped CPW feed. A taper shape slot and rectangular tuning stub fed by microstrip line was presented in [3]. The microstrip antenna combining the Giusepe Peano and Sierpinski Carpet fractal geometries was proposed [4]. In [5], a gradual curvature technique of central line and ground planes of CPW attached to rectangle patch was used for achieving ultra-wide impedance bandwidth. The paper [6] proposed a low-profile 3D antenna structure consisting of a bevel edge feed structure and a metal plate with folded strip. In [7], the microstrip line with balun structures was used as the feeding part of a low profile printed drop-shaped dipole antenna, resulting in a very wide impedance bandwidth suitable for multistandard WLAN/WIMAX/UWB wireless communications. Obviously, the printed planar antennas with various shapes using either microstrip line or CPW for feeding signal capably achieve ultra-wide impedance bandwidth. To confine fabrication tolerance and avoid using of via holes for some MMICs integration, the antenna design using one metallic side on dielectric substrate is proper and the CPW feeding structure possesses these vantages. In this paper, the CPW feeding structure has been chosen. 
The frequency range belonging to $5.15-5.85 \mathrm{GHz}$ has been assigned to the narrow band services including wireless local area network (WLAN) with the IEEE802.11a, HIPERLAN/2 standards and worldwide interoperability for microwave access (WiMAX) with the IEEE802.16e standard. Clearly this frequency range falls within the UWB band resulting in EMIs between both systems. To reject the EMIs for UWB systems, extra band-stop filters should be added. However, these elements lead to a need of more space, higher cost, and more complicate structures. To remedy these problems, an UWB antenna structure, suitable to minimize the EMIs with the R.F. systems working in the frequency band located around $5.5 \mathrm{GHz}$, is strongly desirable. Obviously, the challenge of feasible design for UWB antennas with compact size and the proper electrical characteristics of both frequency and time domain responses would be required. Especially, the potential reduction of EMIs from coexisting WLAN/WiMAX systems is also a necessary characteristic for the UWB antenna design.

Many techniques were employed to design the printed UWB antennas with notched band function. For examples, the technique of embedded one or more narrow slits on the radiating patch for achieving notched band function was proposed in [8-13], the narrow slit embedded on ground plane was used in $[14,15]$, while the spiral stub attached at feed line for band notching was also employed [15]. Parasitic strips coupled with the antennas were also proposed to reject the undesired frequencies [16-18]. In [19-23], a resonator inserted on the patch was proposed for achieving band notching. Additionally, a slit embedded on the ground plane of a printed discone UWB antenna was adopted to reject the undesired frequency bands [22], whereas the resonators nearby feeding line were employed for more notched bands [23]. The embedded narrow slits on the patch and ground plane with resonator on the opposite side of the radiating patch were presented in [24]. The other UWB slot antennas with band notching were proposed in $[25,26]$. The former antenna embeds only a narrow slit on the exciting stub, whereas both a C-shaped narrow slit on the feeding element and a microstrip resonator at the inner slot were employed in the latter antenna. It is clearly seen that the narrow slit with the length of $\lambda_{\mathrm{g}} / 2$ or $\lambda_{\mathrm{g}} / 4$, where $\lambda_{\mathrm{g}}$ is a guided wavelength, is designed by inserting it on either the patch or ground plane for band notching [8-15, 25]. The small coupling parasitic strips or resonators placed, either on the same side or opposite side of the patch, were employed in [16-23], whereas both the narrow slit on the patch and the resonator on the opposite side were used in $[24,26]$. It is apparent that the extra element could be used to reject undesired frequency, but this leads to more complicated structure. Also, using the narrow slits to control the rejected frequency results in many parameters needs to be considered. Besides, utilizing these techniques will be more complicated when applying with real antennas.

In this paper, an embedded filter consisting of a rectangular slot with a quarter-wavelength strip, useful to be employed in a compact UWB antenna to realize a single-band notch at $5.5 \mathrm{GHz}$, is proposed. By integrating the proposed filter in a previous UWB antenna, proposed by the authors in [5], it is easy to reduce the energy emission in the undesired frequency band. The details concerning the antenna design, the parametric study, and the experimental validation will be presented in the following sections.

\section{Antenna Design}

2.1. A Compact UWB Antenna. A compact UWB antenna designed in [5] is used as baseline antenna for this research. All details of the UWB antenna design are briefly described. Figure 1 shows the antenna geometry, the realized prototype, and the simulated and measured return losses of the baseline antenna, respectively. According to the structure in Figure 1(a), the antenna was designed with the height of $0.56 \lambda_{\mathrm{g}}$ and the width of $0.3 \lambda_{\mathrm{g}}$, where $\lambda_{\mathrm{g}}$ is a guided wavelength of the lowest operating frequency. The slot stubs were inserted at the central line of CPW to enhance the impedance matching. As shown in Figure 1(b), the baseline antenna prototype was fabricated on a single metallic side of FR4 substrate with thickness of $1.6 \mathrm{~mm}$, relative permittivity of 4.4, and loss tangent of 0.019. The SMA connector was used for measurement purpose. The measured result shows the extremely large impedance bandwidth $\left(S_{11}<-10 \mathrm{~dB}\right)$ of over $123.23 \%$, covering $2.85 \mathrm{GHz}$ to exceed $12 \mathrm{GHz}$, as shown in Figure 1(c). Although the simulated and measured results show acceptable agreement with some discrepancies, the baseline antenna capably operates covering the entire UWB frequency range. The fabrication tolerances and the discontinuity introduced by the transition between the SMA and the CPW feeding line are responsible for the discrepancies observed in the experimental measurements.

The physical behavior of guided wave to radiated wave on gradual curvature transition was analyzed, resulting in the simulated surface current distribution results on the radiating patch of the baseline antenna at frequencies of $3.1,5,7$, and $9 \mathrm{GHz}$, as shown in Figure 2. It is clearly seen that the surface current distributions are very strong nearby the edges of curvature parts at all frequencies, whereas low current distributions are found on other parts. It is revealed that the gradual curvatures are major parts to radiate wave responding for extremely wide frequency range. On the other hand, when the current distribution paths on gradual curvatures are changed or disturbed, more impact to electrical characteristics of the antenna occurrs. To design the antenna with frequency rejection, the extra element with band notched function is introduced placing nearby the curvature part of radiating patch. In this work, a filter based on a quarter-wavelength strip in rectangular-shaped slot is integrated in the baseline antenna presented in [5] to reduce the energy emission in the frequency band located around $5.5 \mathrm{GHz}$. As it will be shown later, the proposed filter does not significantly affect the impedance bandwidth of the baseline antenna. Therefore, the conductor on patch is etched out with appropriate dimensions to form the rectangular-shaped slot.

\subsection{Design of the Filter Integrated into the UWB Antenna.} The mitigation of the EMIs in the frequency band centered around $5.5 \mathrm{GHz}$ can be achieved by using a suitable filter integrated in the antenna structure. As mentioned, the notched band function could be applied to the baseline UWB 


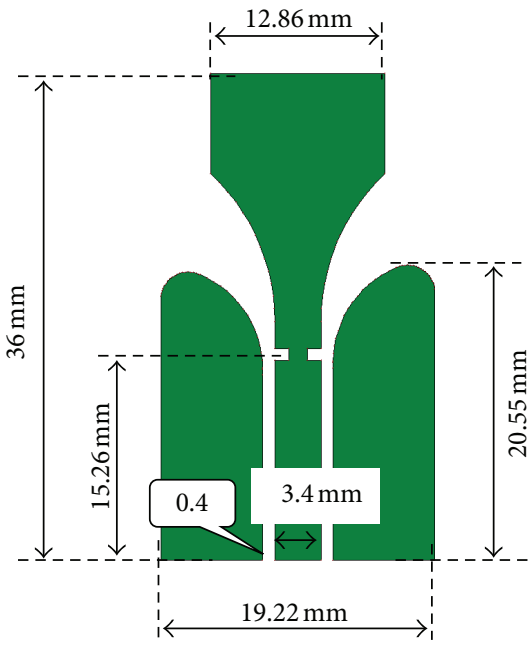

(a)
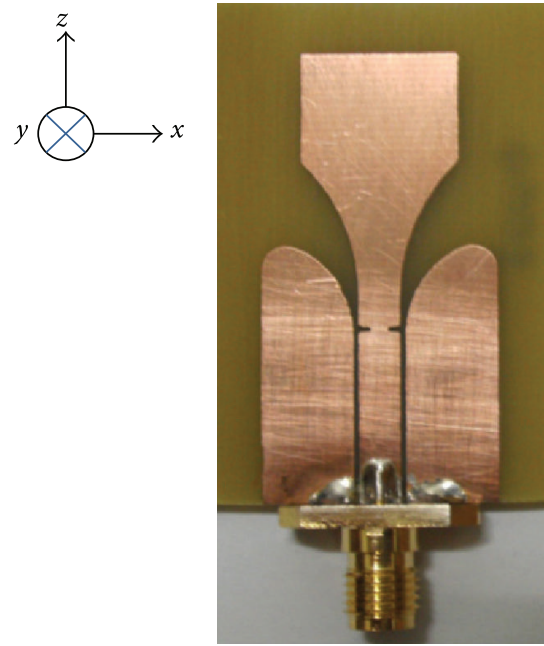

(b)

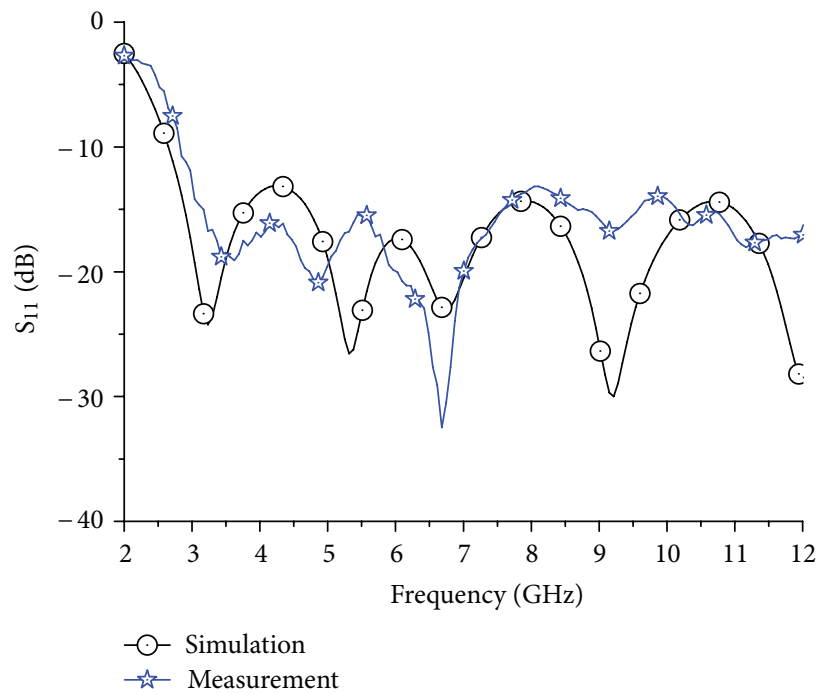

(c)

FIGURE 1: The baseline UWB antenna: (a) configuration, (b) the prototype, and (c) comparison return loss of simulated and measured results of the baseline antenna prototype.

antenna structure. In this work, two designed steps for the notched band are applied. Firstly, the proper rectangularshaped slot, with $w_{s}$ of $2.25 \mathrm{~mm}$ and $h_{s}$ of $8.11 \mathrm{~mm}$, is formed on the patch, as shown in Figure 3(a). Secondly, a small strip is placed at the lower inner edge of a rectangle slot (see Figure 3(a)). The length of this strip, which is about a quarterwavelength at the rejected frequency of $5.5 \mathrm{GHz}$, is calculated as follows:

$$
f_{\text {reject }} \cong \frac{3 \times 10^{8}}{4 l_{s} \times \sqrt{\varepsilon_{\text {eff }}}} \quad \mathrm{Hz}
$$

where

$$
\varepsilon_{\mathrm{eff}} \approx\left(\frac{\varepsilon_{r}+1}{2}\right)
$$

From (1), the relative permittivity of dielectric and the length of small strip are denoted by $\varepsilon_{r}$ and $l_{s}$, respectively.
As seen in Figure 3(a), the small strip is inserted into the rectangular slot for band notching. A comparison of simulated return loss results, when varying the small strip length $\left(l_{s}\right)$, is given in Figure 3(b). The other parameters are fixed when the $l_{s}$ parameter is varied. Whereas the length of small strip is extended, the rejected frequency is moved to lower frequencies and vice versa. The proposed antenna capably rejects the frequency of $5.5 \mathrm{GHz}$ by setting the optimal small strip length to be $7.27 \mathrm{~mm}$. It is obvious that the length of small strip corresponds to an approximate quarter-wavelength at the rejected frequency. It can be concluded that the rejected frequency is controlled by the length of the small strip. Apparently, the rejection of the undesired frequency can be achieved as in the previous work in [9]. However, the structure proposed to reject the undesired frequency is more simple and easy to design since it requires the optimization of only one parameter. 


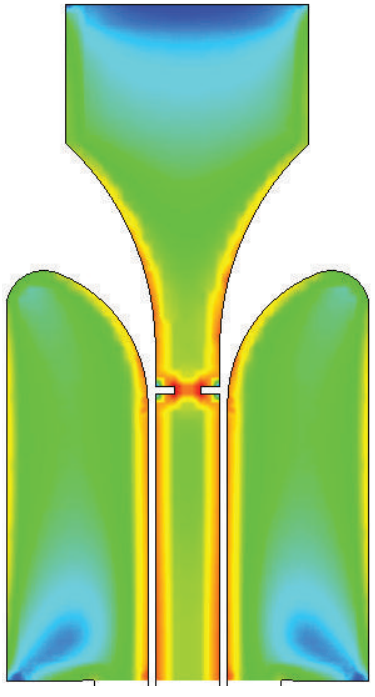

(a)

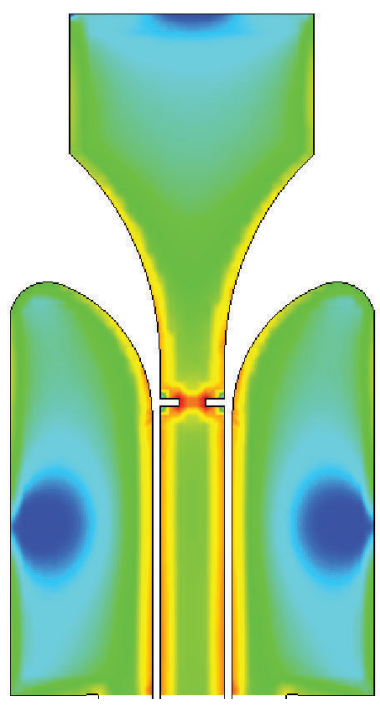

(c)
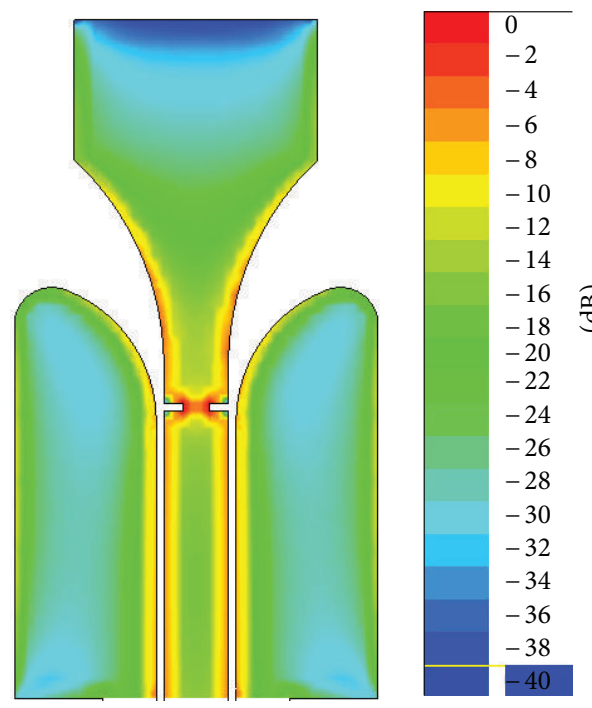

Normalized scale

(b)

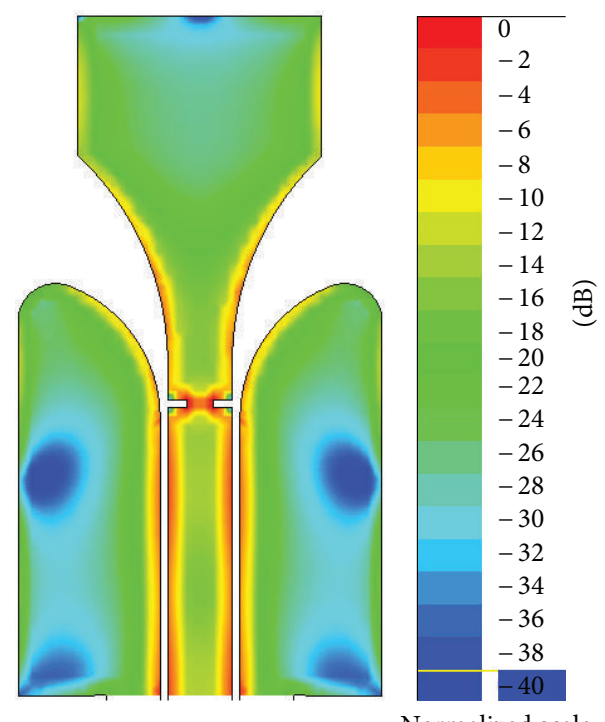

Normalized scale

(d)

FIGURE 2: Simulated surface current distribution of the baseline antenna at frequencies of (a) $3.1 \mathrm{GHz}$, (b) $5 \mathrm{GHz}$, (c) $7 \mathrm{GHz}$, and (d) $9 \mathrm{GHz}$.

Figure 3(c) depicts the simulated return loss results when the $h_{r}$ parameter, indicating the position of rectangular slot with the quarter-wavelength strip on the radiating patch, is varied. The other parameters are fixed when the $h_{r}$ parameter is varied. It is seen that the notched bandwidth is slightly increased, whereas the $h_{r}$ parameter is decreased and vice versa. While the $h_{r}$ parameter is decreased, the rectangular slot with the quarter-wavelength strip is moved toward the gradual curvature parts. The electromagnetic coupling between the radiated parts and the quarter-wavelength strip is also increased. As a result, there is a significant change in input impedance of the antenna leading to mismatching and higher reflection coefficients. The characteristic impedance is significantly affected, resulting in a wider notched bandwidth. The optimal $h_{r}$ parameter of $17.4 \mathrm{~mm}$ capably provides the notched bandwidth of $5.2-5.8 \mathrm{GHz}$. It is concluded that the notched bandwidth is controlled by the position of rectangular slot with the quarter-wavelength strip on radiating patch. In addition, the widths of quarterwavelength strip and rectangular slot are fixed due to limited area on the patch.

The physical mechanism governing the behavior of the filter integrated into the antenna can be clarified using the surface current map excited in the vicinity of the filter's strip (see Figure 4). In particular, from Figure 4 it appears that at $5.5 \mathrm{GHz}$ the surface current distribution is strongly concentrated in the lowerpart of the filter close the radiating part of the antenna. This feature is responsible for a strong reflection 


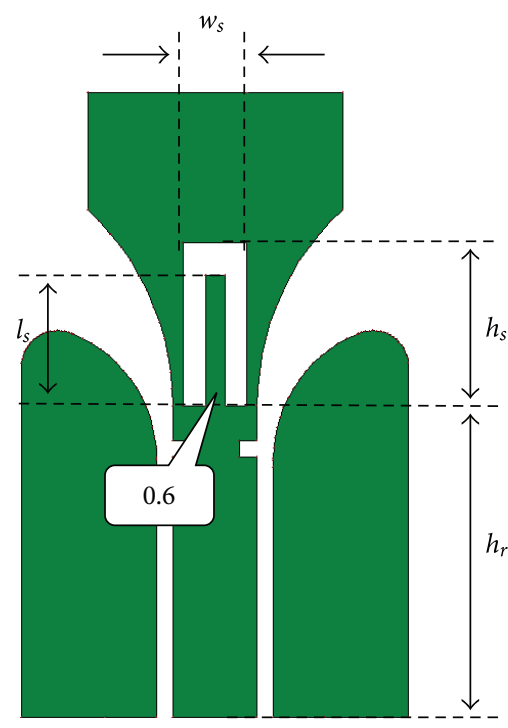

(a)

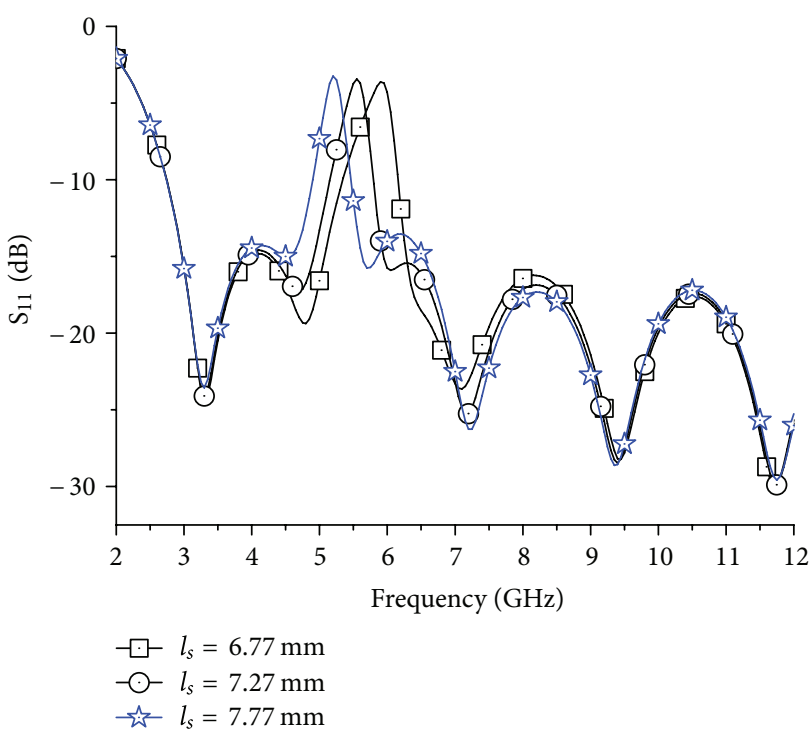

(b)

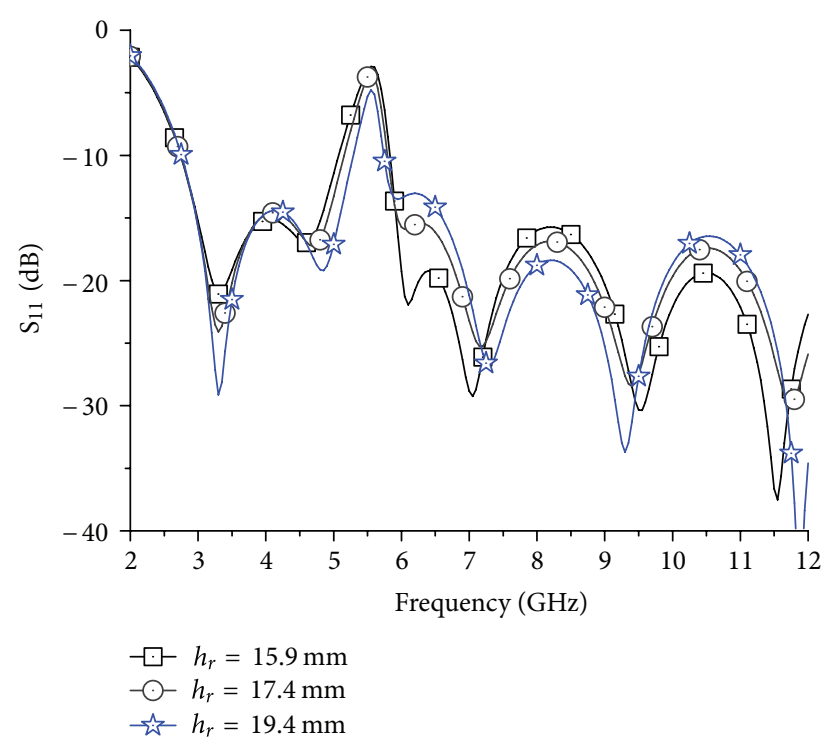

(c)

Figure 3: (a) Configuration of the proposed antenna, (b) $S_{11}$ results when varying $l_{s}$, and (c) $S_{11}$ results when varying $h_{r}$.

of the surface current, which determines an increment of the related return loss.

\section{Implementation and Measurement Results}

The proposed antenna has been realized using the optimized parameters obtained by means of the full-wave software Zeland IE3D. Photograph of the proposed antenna prototype is shown in Figure 5(a). The SMA connector is also employed to feed the signal for measurement purpose. A comparison of return losses between measured and simulated results is illustrated in Figure 5(b). From measured result, it is seen that the prototype antenna capably provides the operating frequency covering the entire UWB range and achieves the requirement of notched frequency range from 5.1 to
5.75 GHz. Besides, it is found that the center frequency of notched band slightly shifts to lower frequency. At lower band of $3.1-5 \mathrm{GHz}$, the lower edge frequency and the resonant frequency shift to higher; on the contrary, the resonant frequencies evidently shift to lower frequency at higher band of 6-10.6 GHz. The fabrication tolerances, the discontinuity introduced by transition between the SMA and CPW transmission line, and some inevitable nonuniformity of the substrate characteristics are the main causes of these unexpected behaviors.

The measured radiation pattern results of the proposed antenna at the frequencies of $3.1,5,7$, and $9 \mathrm{GHz}$ in $x y$ and $y z$ planes are illustrated in Figure 6. The measured copolarization is denoted by solid line with circle and star symbols, while the measured cross-polarization is denoted 


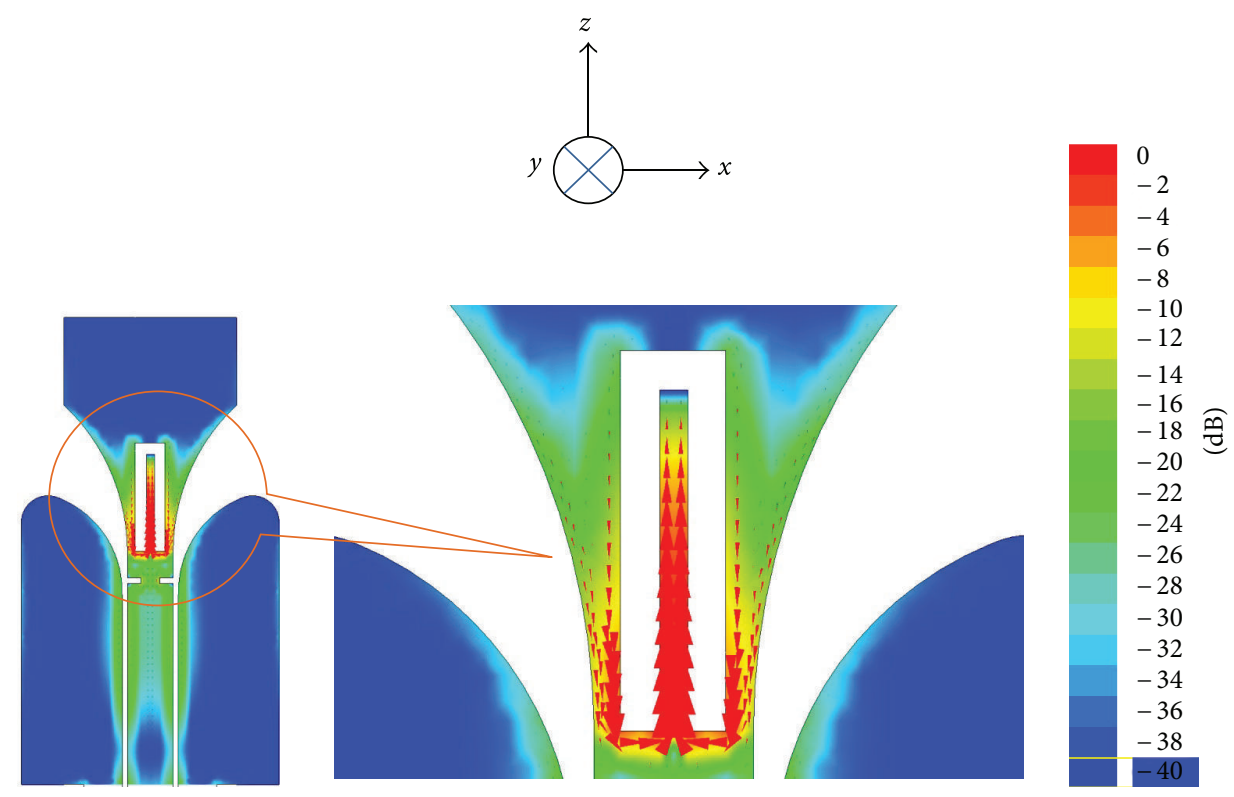

FIGURE 4: Surface current density excited near the filter's strip at the frequency of $5.5 \mathrm{GHz}$.

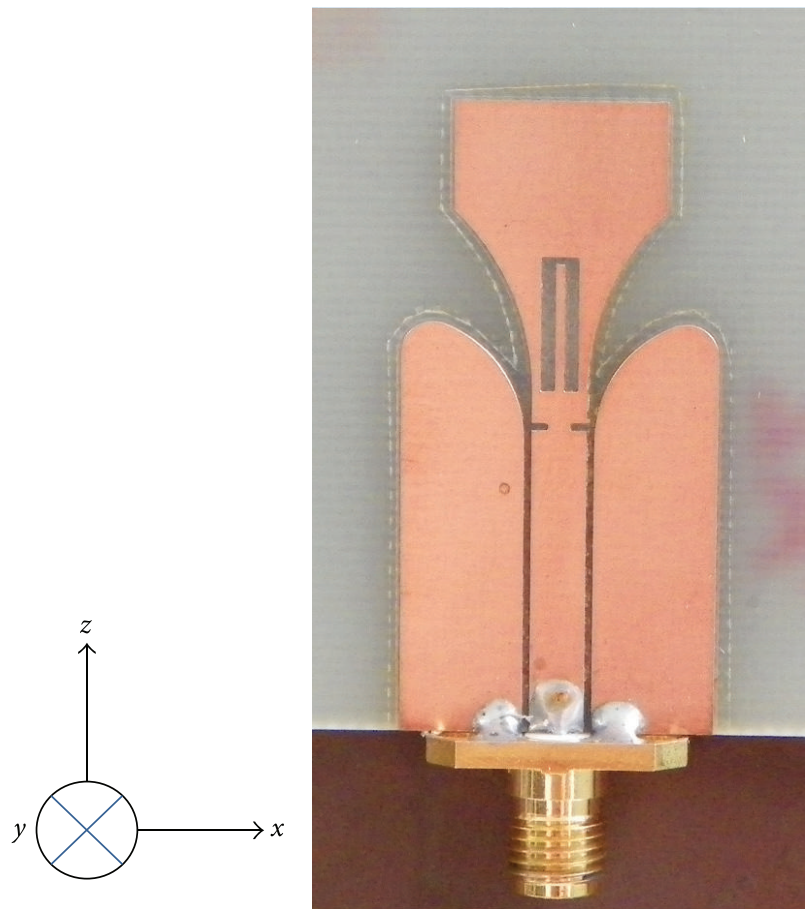

(a)

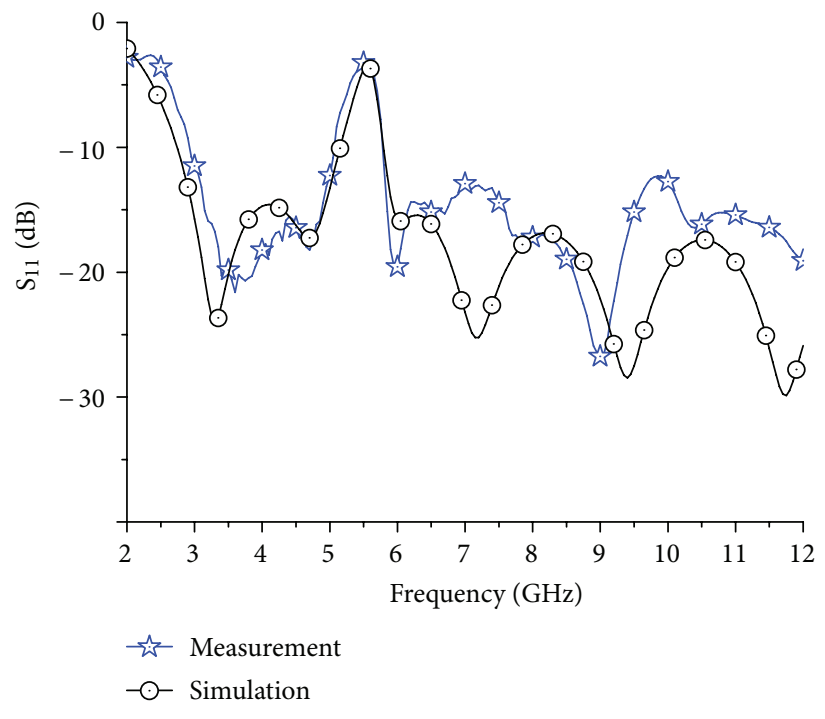

(b)

FIGURE 5: (a) The prototype antenna and (b) comparison of simulated and measured return losses.

by dash line with cross on triangle and rhombus symbols. In $x y$ plane, radiation patterns of the proposed antenna show nearly to be omnidirectional at all frequencies, as shown in Figures 6(a) and 6(b). Additionally, the high level of crosspolarization occurring at the frequencies of 3.1 and $5 \mathrm{GHz}$ is due to the strong deformation of the current paths caused by the presence of the quarter-wavelength strip and rectangular slot filter. The measured radiation patterns in $y z$ plane are shown in Figures 6(c) and 6(d). The radiation patterns at all frequencies show likely bi-directional with some distortions due to some spurious emissions. The proposed antenna capably affords linear polarization.

The transfer function $\left(S_{21}\right)$ and group delay time are measured by setting up two identical antennas face to face 


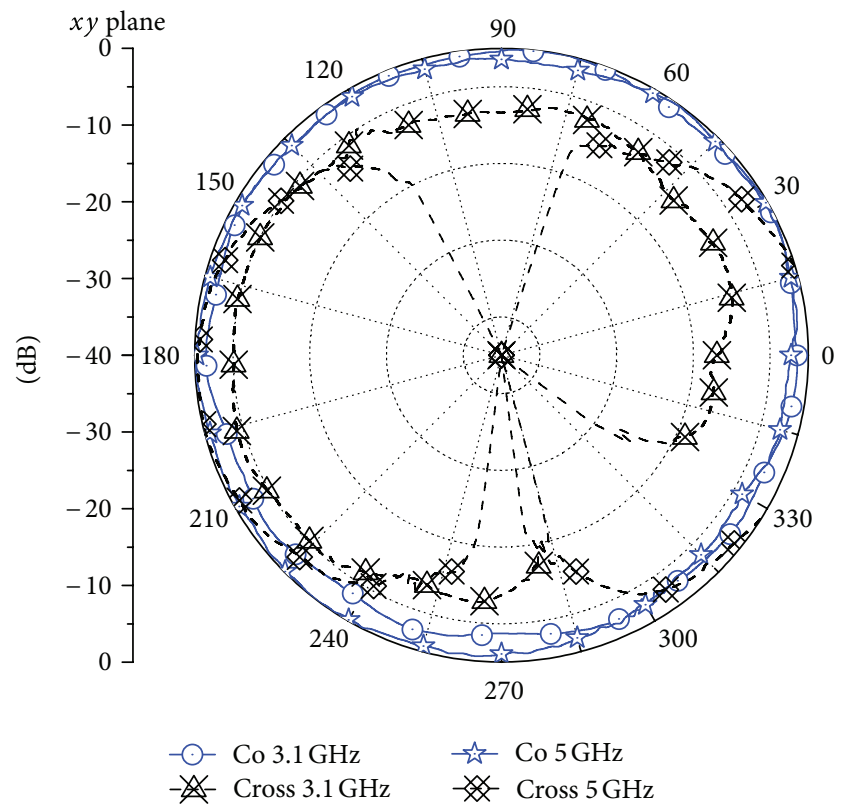

(a)

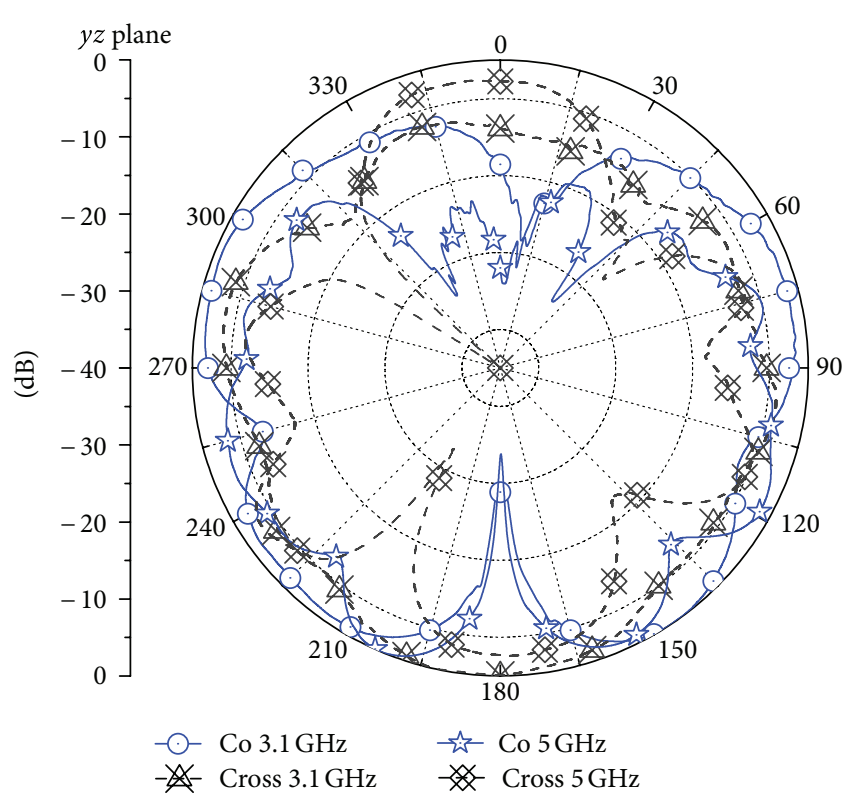

(c)

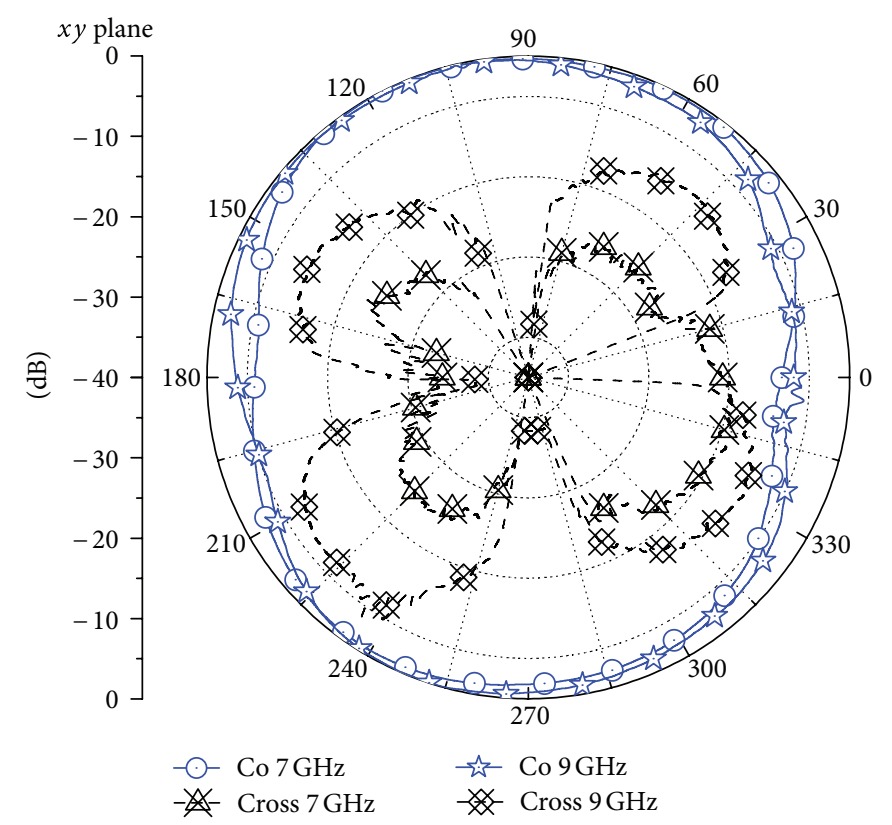

(b)

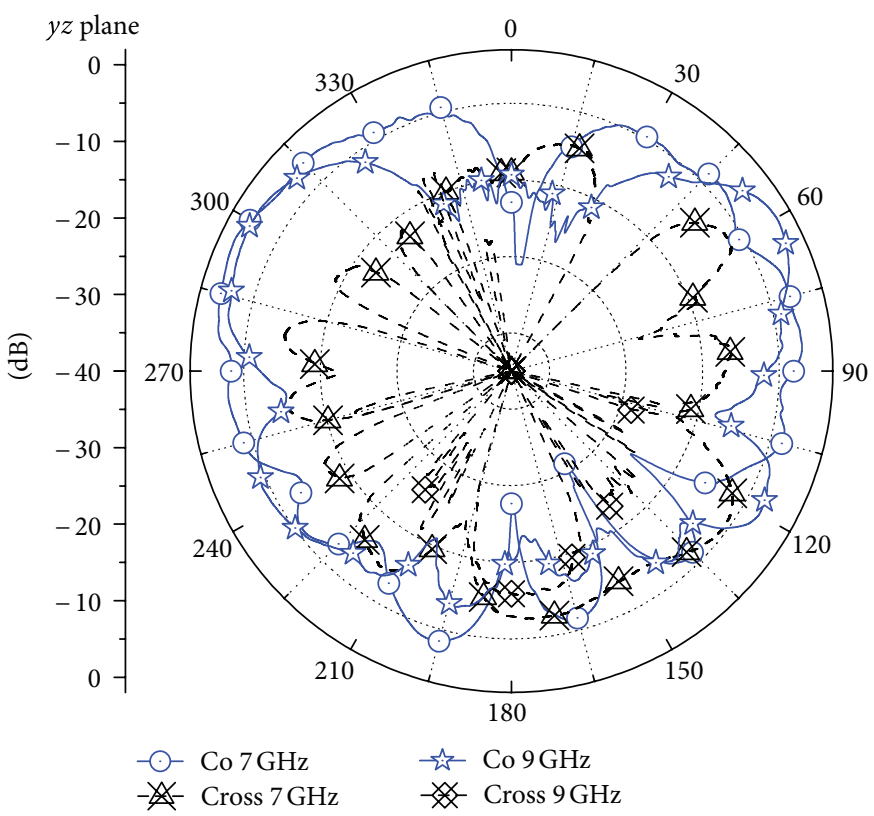

(d)

FIGURE 6: Measured radiation patterns at the frequencies of (a) 3.1, $5 \mathrm{GHz}$, (b) 7, $9 \mathrm{GHz}$ in $x y$ plane, and (c) $3.1,5 \mathrm{GHz}$, (d) $7,9 \mathrm{GHz}$ in $y z$ plane.

with distance of $0.35 \mathrm{~m}$. Comparisons of measured transfer function and group delay time between the proposed antenna and the previous antenna (in [9]) are illustrated in Figures 7 (a) and 7(b), respectively. It can be found that the transfer function of the proposed antenna prototype has been slightly improved with better frequency rejection. Both transfer function and group delay time obtained in this work are slightly more constant than the previous antenna due to the simple notched band structure.
Figure 8(a) depicts measured time domain characteristic results of the proposed antenna. It is seen that the transfer function is deeply sharp, which is $-53.18 \mathrm{~dB}$ at the notched band center. The pass band across from 3.1 to $9 \mathrm{GHz}$ affords the average $S_{21}$ levels higher than $-43.85 \mathrm{~dB}$. When the frequency is over $9.2 \mathrm{GHz}$, the $S_{21}$ gradually decreases and reaches minimum level of $-50 \mathrm{~dB}$ at the frequency of $10.6 \mathrm{GHz}$. The constant group delay time of the proposed antenna presents an almost constant value within the working 


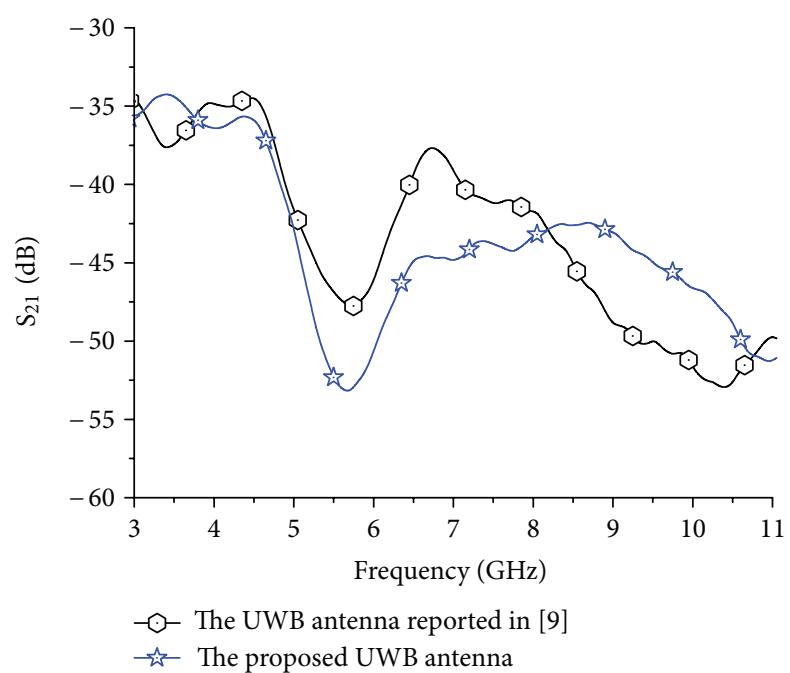

(a)

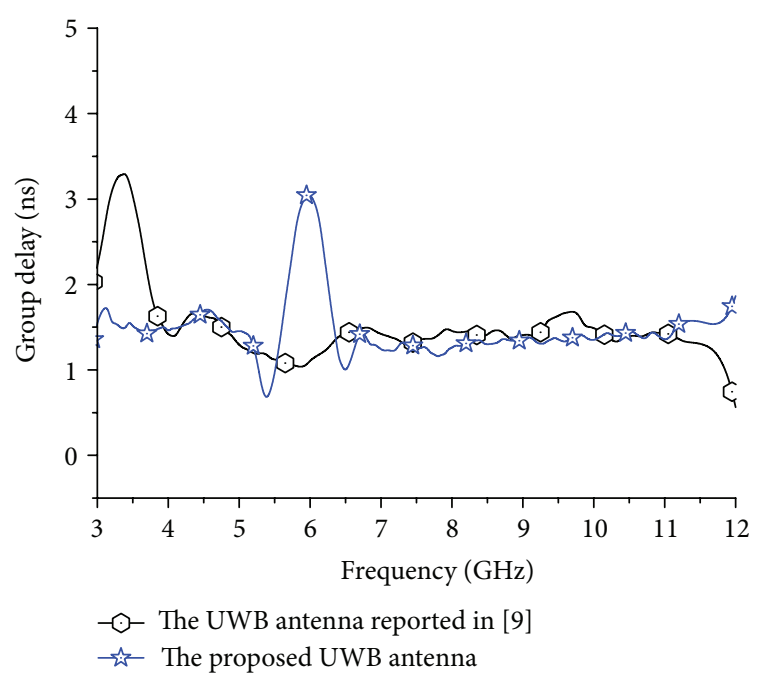

(b)

FIGURE 7: Comparison between the previous antenna and the proposed antenna (a) transfer function and (b) group delay time.

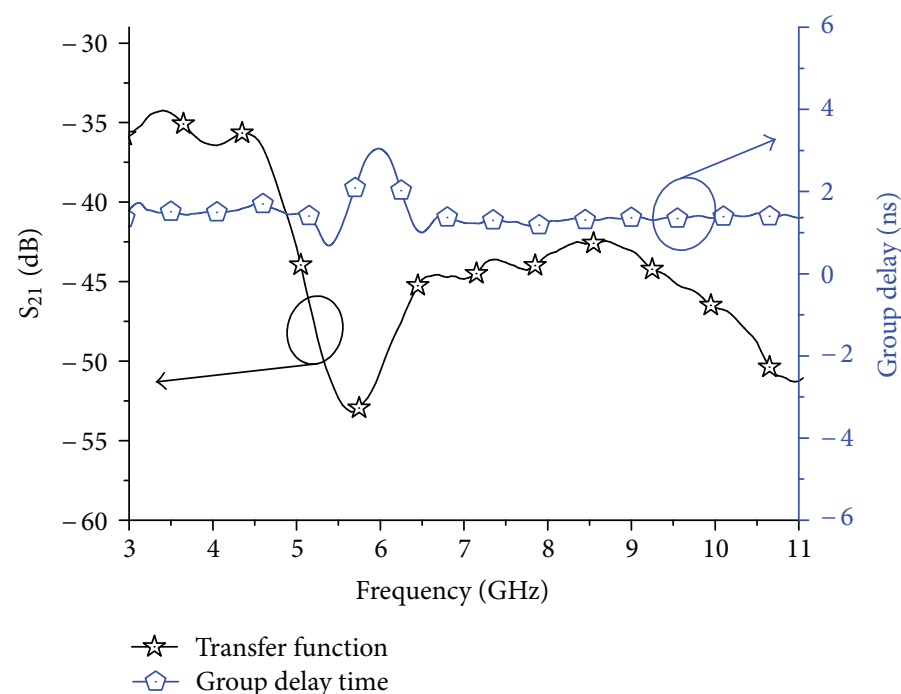

(a)

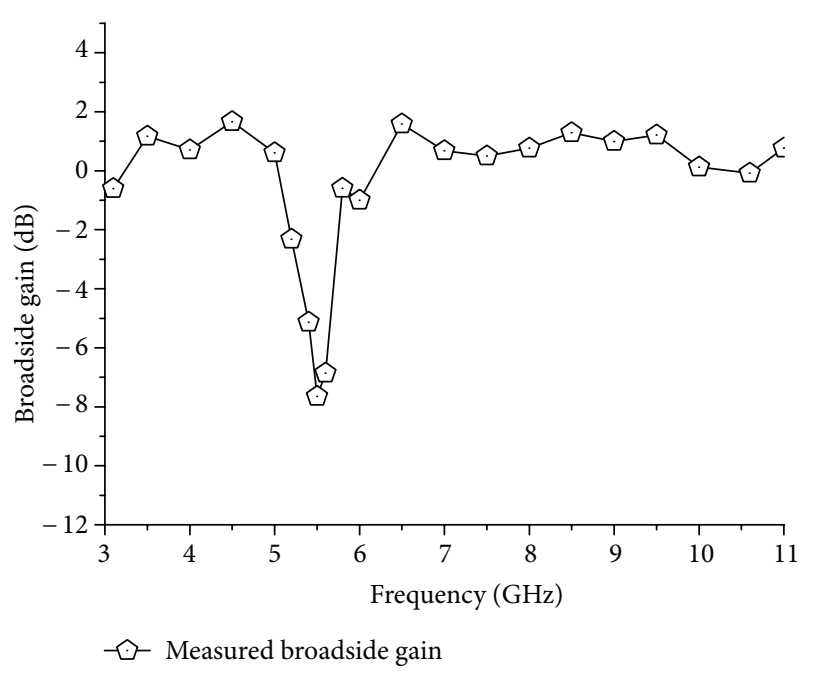

(b)

FIGURE 8: (a) Measured transfer function and group delay time and (b) measured broadside gain of the proposed antenna.

frequency bands, while in the notched band it exhibits a peak value of about $3 \mathrm{~ns}$. It is indicated that the proposed antenna capably operates with good linear transmission performances and may be used for impulse radio applications with a little distortion. The measured broadside gain result of the proposed antenna is given, as shown in Figure 8(b). It is found that the antenna gain fluctuates within the range of -0.6 to $1.6 \mathrm{~dB}$ at the lower band of $3.1-5 \mathrm{GHz}$, and the maximum value is occurred at frequency of $4.5 \mathrm{GHz}$. The antenna gain is deeply sharp, which is $-7.6 \mathrm{~dB}$ at the notched band center. At the higher band of 6-10.6 GHz, the measured broadside gain shows more constant than the lower band, and the maximum value of $1.6 \mathrm{~dB}$ is given at frequency of $6.5 \mathrm{GHz}$.

\section{Conclusion}

A compact UWB antenna with band notching at $5.5 \mathrm{GHz}$ is proposed. All the details concerning the antenna design and the frequency behavior of the band notch filter have been presented. The rectangular slot is embedded into the radiating patch of the previous UWB antenna. The small strip with its length approximately a quarter-wavelength of $5.5 \mathrm{GHz}$ is attached to the lower inner edge of the rectangular slot for band notching. The strong current distribution concentrates on the quarter-wavelength strip and lower part rectangular slot leading to a drastic change into the input impedance of the antenna. The high reflection coefficients and mismatching 
of the input impedance occurred. Consequently, the amplitude of the radiated field decreases since the level of the surface current excited in the radiating part of the antenna has reduced. The center rejected frequency is controlled by adjusting the length of the quarter-wavelength strip. The notched frequency bandwidth is depended on the position of rectangular slot with the quarter-wavelength strip on radiating patch. The proposed antenna operates covering the entire UWB band except the notched band of 5.1-5.75 GHz. Having the minimized EMIs potential at frequency band of $5.5 \mathrm{GHz}$ and radiation patterns nearly omnidirectional at all frequencies in $x y$ plane, the proposed antenna is appropriate to use for various UWB applications.

\section{Conflict of Interests}

This paper has supported the framework of a Ph.D. thesis. The authors declare that there is no conflict of interests with IE3D software.

\section{References}

[1] N. Fortino, J. Y. Dauvignac, G. Kossiavas, and R. Staraj, "Design optimization of UWB printed antenna for omnidirectional pulse radiation," IEEE Transactions on Antennas and Propagation, vol. 56, no. 7, pp. 1875-1881, 2008.

[2] C. Deng, Y. J. Xie, and P. Li, "CPW-fed planar printed monopole antenna with impedance bandwidth enhanced," IEEE Antennas and Wireless Propagation Letters, vol. 8, pp. 1394-1397, 2009.

[3] R. Azim, M. T. Islam, and N. Misran, "Compact tapered-shape slot antenna for UWB applications," IEEE Antennas and Wireless Propagation Letters, vol. 10, pp. 1190-1193, 2011.

[4] H. Oraizi and S. Hedayati, "Miniaturized UWB monopole microstrip antenna design by the combination of Giusepe Peano and Sierpinski carpet fractals," IEEE Antennas and Wireless Propagation Letters, vol. 10, pp. 67-70, 2011.

[5] P. Moeikham and P. Akkaraekthalin, "A compact ultrawideband monopole antenna with tapered CPW Feed and slot stubs," in Proceedings of the 8th International Conference on Electrical Engineering/ Electronics, Computer, Telecommunications and Information Technology (ECTI-CON '11), pp. 180-183, Khon Kaen, Thailand, May 2011.

[6] C.-H. Kang, S.-J. Wu, and J.-H. Tarng, "A novel folded UWB antenna for wireless body area network," IEEE Transactions on Antennas and Propagation, vol. 60, no. 2, pp. 1139-1142, 2012.

[7] G. Cappelletti, D. Caratelli, R. Cicchetti, and M. Simeoni, "A low-profile printed drop-shaped dipole antenna for wideband wireless applications," IEEE Transactions on Antennas and Propagation, vol. 59, pp. 3526-3535, 2011.

[8] L. Lizzi, G. Oliveri, P. Rocca, and A. Massa, "Planar monopole UWB antenna with UNII1/UNII2 WLAN-band notched characteristics," Progress in Electromagnetics Research B, no. 25, pp. 277-292, 2010.

[9] P. Moeikham, C. Mahatthanajatuphat, and P. Akkaraekthalin, "A compact ultrawideband monopole antenna with $5.5 \mathrm{GHz}$ notched band," Progress in Electromagnetics Research C, vol. 26, pp. 13-27, 2012.

[10] Q. X. Chu and Y. Y. Yang, "A compact ultrawideband antenna with $3.4 / 5.5 \mathrm{GHz}$ dual band-notched characteristics," IEEE Transactions on Antennas and Propagation, vol. 56, no. 12, pp. 3637-3644, 2008.
[11] T. D. Nguyen, D. H. Lee, and H. C. Park, "Design and analysis of compact printed triple band-notched UWB antenna," IEEE Antennas and Wireless Propagation Letters, vol. 10, pp. 403-406, 2011.

[12] D. T. Nguyen, D. H. Lee, and H. C. Park, "Very compact printed triple band-notched UWB antenna with quarter-wavelength slots," IEEE Antennas and Wireless Propagation Letters, vol. 11, pp. 411-414, 2012.

[13] X.-J. Liao, H.-C. Yang, N. Han, and Y. Li, "UWB antenna with dual narrow band notches for lower and upper WLAN bands," Electronics Letters, vol. 46, pp. 1593-1594, 2010.

[14] Y.-B. Yang, F.-S. Zhang, F. Zhang, L. Zhang, and Y.-C. Jiao, "Design of novel wideband monopole antenna with a tunable notched-band for 2.4 GHZ WLAN and UWB applications," Progress in Electromagnetics Research Letters, vol. 13, pp. 93-102, 2010.

[15] S. K. Mishra and J. Mukherjee, "Compact printed dual bandnotched U-shape UWB antenna," Progress in Electromagnetics Research C, vol. 27, pp. 169-181, 2012.

[16] A. M. Abbosh and M. E. Bialkowski, "Design of UWB planar band-notched antenna using parasitic elements," IEEE Transactions on Antennas and Propagation, vol. 57, no. 3, pp. 796-799, 2009.

[17] M. Zhang, Y. Z. Yin, J. Ma, Y. Wang, W. C. Xiao, and X. J. Liu, "A racket-shaped slot UWB antenna coupled with parasitic strips for band-notched application," Progress in Electromagnetics Research Letters, vol. 16, pp. 35-44, 2010.

[18] Y. Zhu, F. S. Zhang, C. Lin, Y. C. Jiao, and R. Zou, "Design of band-notched structure for UWB applications," Electronics Letters, vol. 47, no. 4, pp. 235-236, 2011.

[19] S. J. Wu and J. H. Tarng, "Planar band-notched ultra-wideband antenna with square-looped and end-coupled resonator," IET Microwaves, Antennas and Propagation, vol. 5, no. 10, pp. 1227-1233, 2011.

[20] S. J. Wu, C. H. Kang, K. H. Chen, and J. H. Tarng, "Study of an ultrawideband monopole antenna with a band-notched open-looped resonator," IEEE Transactions on Antennas and Propagation, vol. 58, no. 6, pp. 1890-1897, 2010.

[21] C. Y. Hong, C. W. Ling, I. Y. Tarn, and S. J. Chung, "Design of a planar ultrawideband antenna with a new band-notch structure," IEEE Transactions on Antennas and Propagation, vol. 55, no. 12, pp. 3391-3397, 2007.

[22] X. Li, H. L. Zheng, T. Quan, and Q. Chen, "A printed discone ultra-wideband antenna with dual-band notched characteristics," Progress in Electromagnetics Research C, vol. 27, pp. 41-53, 2012.

[23] C. Lin, P. Jin, and R. W. Ziolkowski, "Single, dual and tri-bandnotched ultrawideband (UWB) antennas using capacitively loaded loop (CLL) resonators," IEEE Transactions on Antennas and Propagation, vol. 60, no. 1, pp. 102-109, 2012.

[24] W. T. Li, X. W. Shi, and O. Q. Hei, "Novel planar UWB monopole antenna with triple band-notched characteristics," IEEE Antennas and Wireless Propagation Letters, vol. 8, pp. 1094-1098, 2009.

[25] S. Mohammadi, J. Nourinia, C. Ghobadi, and M. Majidzadeh, "Compact CPW-fed rotated square-shaped patch slotantenna with band-notched function for UWBapplications," Electronics Letters, vol. 47, pp. 1307-1307, 2011.

[26] G. P. Gao, Z. L. Mei, and B. N. Li, "Novel circular slot UWB antenna with dual band-notched characteristic," Progress in Electromagnetics Research C, vol. 15, pp. 49-63, 2010. 

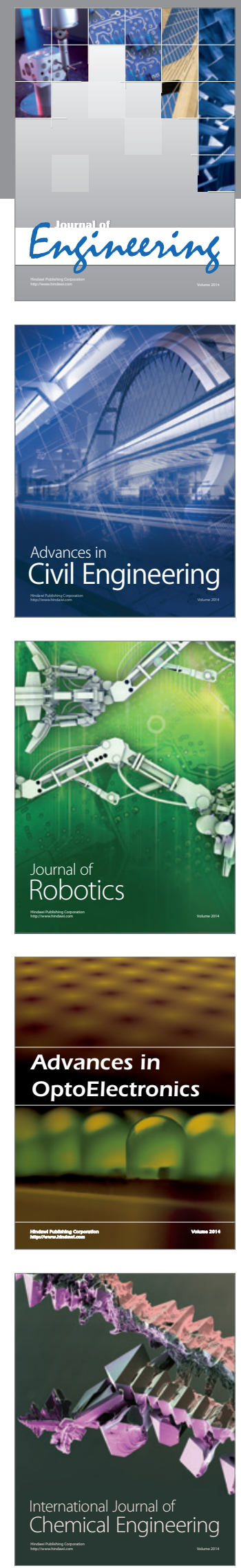

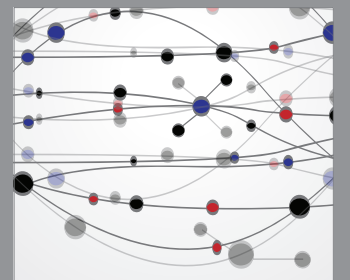

The Scientific World Journal
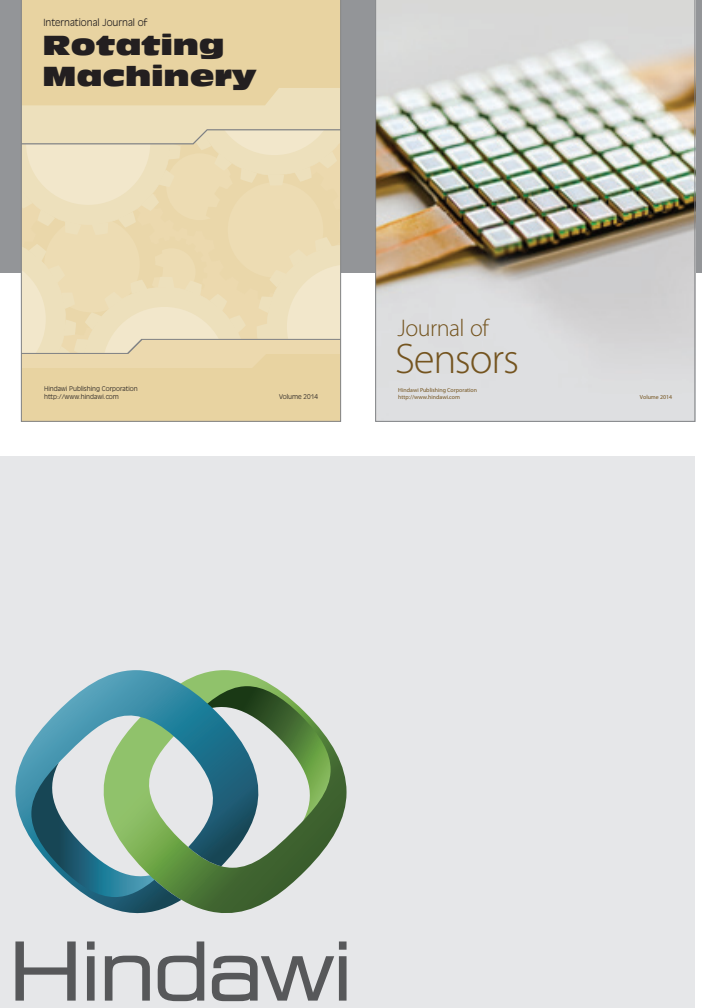

Submit your manuscripts at http://www.hindawi.com
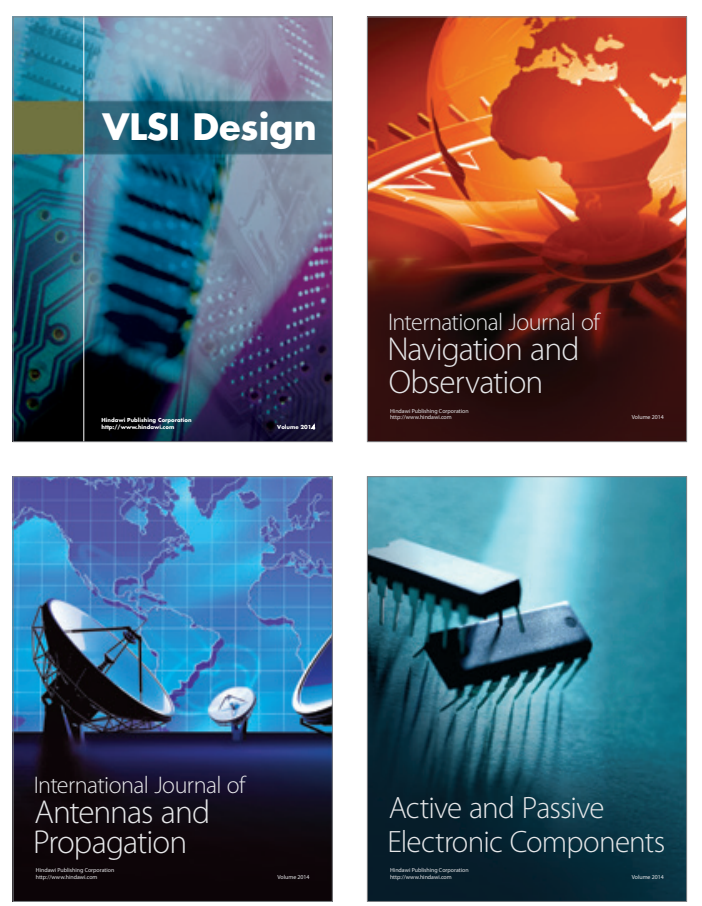
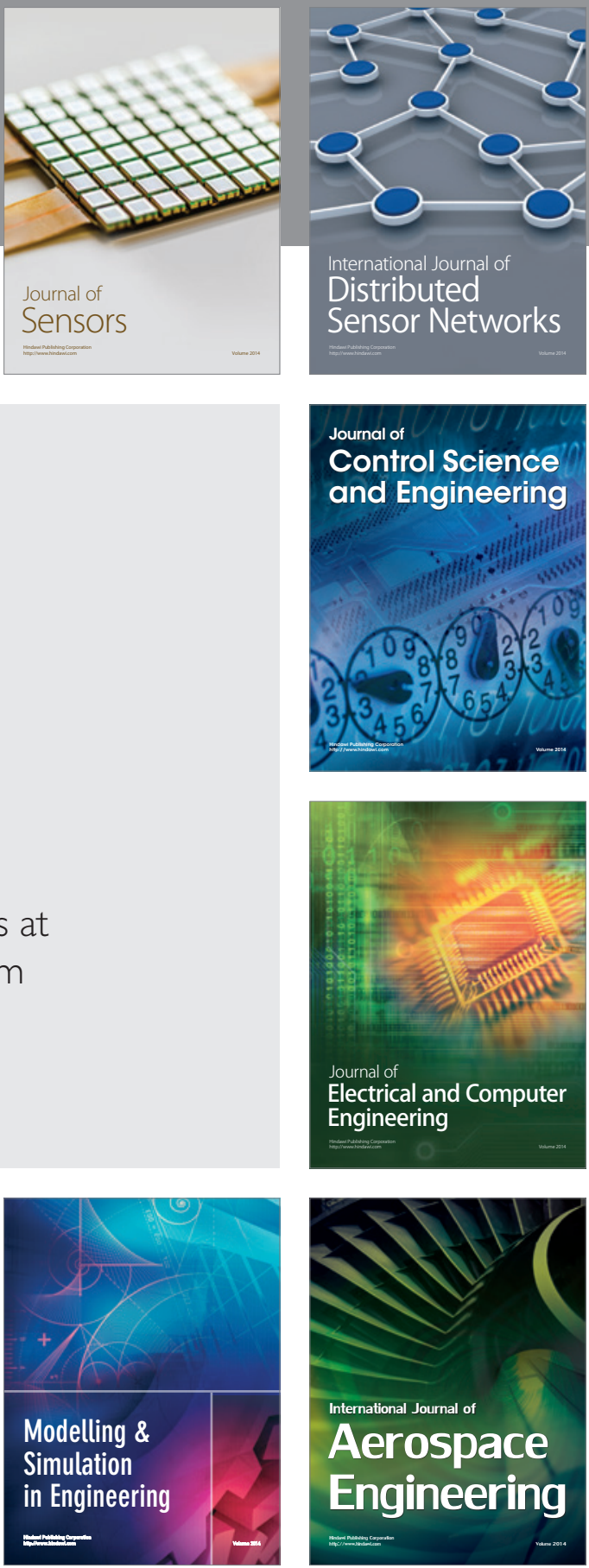

Journal of

Control Science

and Engineering
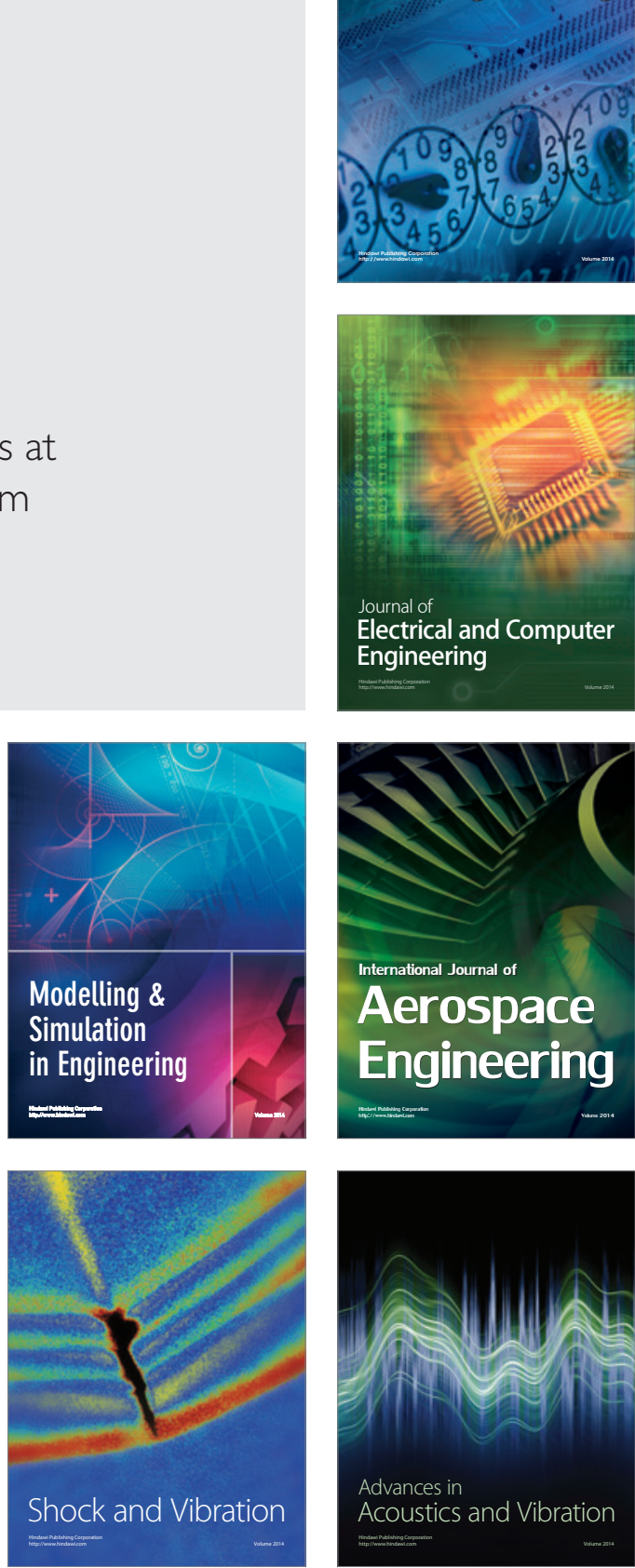